\title{
Letrozole Ovarian Stimulation improves Outcome of Endometrial Scratching prior to Intrauterine Insemination Procedure
}

\author{
Original \\ Article \\ Ahmed M Hagras ${ }^{1}$ and Ehab Barakat ${ }^{2}$ \\ ${ }^{I}$ Departments of Obstetrics and Gynecology, Faculty of Medicine, Tanta Universities \\ ${ }^{2}$ Departments of Obstetrics and Gynecology, Faculty of Medicine, Benha Universities
}

\begin{abstract}
Aim of the work: To compare the outcome of intrauterine insemination (IUI) after letrozole (LET) ovarian stimulation (OS) followed by endometrial scratching (ES) versus after each intervention separately.

Patients and Methods: This study included 90 women with primary infertility for $>2$ years secondary to male factor and had previous failed IUI or expectant trials. All women underwent clinical examination and transvaginal ultrasonographic (TUV) examination and hormonal profile. Enrolled couples were randomly divided into three groups: Group L received oral letrozole $5 \mathrm{mg}$ from day 3 to 7 of the menstrual cycle, Group S included females subjected to ES injury and Group LS included females received LET OS followed by ES injury. For all groups, ovulation was monitored and assured using TVU for evident ovulation with a dominant follicle size $>18 \mathrm{~mm}$. IUI was repeated for three cycles and clinical pregnancy rate (CPR) and abortion and multiple pregnancy rates were recorded.

Results: The studied women gave 287 follicles of $>18 \mathrm{~mm}$ with a mean number of follicles of 3.18/female and 1.35/ cycle. Mean endometrial thickness was significantly lower, while E2 serum levels were significantly higher in women of group S compared to women of other groups. Total CPR was $41.1 \% /$ woman and $17.4 \%$ /cycle with significant difference in favor of group LS. Two patients of groups L and LE had multiple pregnancy and 5 women had abortion for a rate of $5.6 \%$ /woman and $2.3 \%$ /cycle.

Conclusion: Letrozole OS did better to prepare for IUI in infertile couple secondary to male subfertility. ES prior to IUI improved the chances of clinical pregnancy and could be an alternative to OS whenever OS had failed or contraindicated. ES after letrozole OS followed by IUI augments the CPR up to 53.3\%/patient.
\end{abstract}

Key Words: Clinical pregnancy rate, Endometrial scratch, Intrauterine insemination, Letrozole ovarian stimulation, Male factor infertility.

Received: 17 August 2018, Accepted: 11 September 2018

Corresponding Author: Ehab Barakat, MD, Departments of Obstetrics and Gynecology, Faculty of Medicine, Benha Universities, Cairo, Egypt, E-mail: drehabmarzouk@yahoo.com, Tel.: +20 1114346252

ISSN: 2090-7265, February 2019, Vol. 9, No. 1

\section{INTRODUCTION}

High number of infertile people requires assisted reproduction techniques (ART) ${ }^{[1]}$. The frequently used fertility treatments for couples with male subfertility include intra-uterine insemination (IUI), in-vitro fertilization (IVF) and intracytoplasmic sperm injection (ICSI) ${ }^{[2]}$.

IUI involves the direct intrauterine placement of sperm at time of ovulation in natural menstrual cycle or following ovarian stimulation $(\mathrm{OS})^{[3]}$. IUI procedure increases the chance for maximum number of healthy sperm to reach the site of fertilization and efficiently performed IUI gives pregnancy rates equally good to $\mathrm{IVF}^{[4]}$. Moreover, IUI yields a higher cumulative pregnancy rate than intracervical insemination in both natural and stimulated cycles $^{[5]}$.
Embryo implantation is a critical step in establishment of pregnancy ${ }^{[6]}$. Endometrial receptivity refers to the ability of endometrium to accept and accommodate endometrial embryo implantation during the implantation window period ${ }^{[7]}$ which extends between days 5 and 10 following the luteinizing hormone surge ${ }^{[8]}$. Endometrial receptivity is an important factor affecting the rate of blastocyst implantation in $\mathrm{ART}^{[9]}$ and in recurrent implantation failure of endometrial origin a displaced window of implantation leading to desynchronization between the blastocyst and the endometrium ${ }^{[10]}$.

Aromatase is a microsomal member of the cytochrome P450 hemoprotein-containing enzyme complex superfamily ${ }^{[1]}$ that synthesizes estrogens by catalyzing the three consecutive hydroxylation reactions to convert C19 androgens to aromatic C18 estrogenic steroids ${ }^{[12]}$. 
Aromatase is expressed in a tissue-specific manner and its activity can be demonstrated in several tissues, including the endometrium ${ }^{[13]}$, ovaries ${ }^{[14]}$, breast and estrogendependent breast cancer ${ }^{[15]}$.

\section{Hypothesis}

This study hypothesized that letrozole (LET) ovarian stimulation (OS) followed by endometrial scratch (ES) before IUI improves its outcome than each intervention performed separately.

\section{AIM OF WORK}

To compare the outcome of IUI after letrozole OS followed by ES versus after each intervention separately.

Setting: Tanta and Benha University Hospitals

Design: Comparative multicenter clinical trial

\section{PATIENTS AND METHODS}

The study protocol was approved by the Local Ethical Committees. All couples had primary infertility for $>2$ years secondary to male factor and had previous failed IUI or expectant trials were eligible for evaluation. Females with hyperprolactinemia, thyroid dysfunction, Cushing's syndrome, congenital adrenal hyperplasia, adrenal tumor or ovarian tumor, autoimmune disease, malignancy, central nervous system disease, infertility for causes other than male factor infertility were excluded from the study. Also, women with intrauterine anomalies were excluded from the study. Males with hormonal abnormalities, obstructive vas lesions, processed total motile sperm count (PTMS) of $<5$ million $^{[16]}$, infection manifested as high total leucocytic count or presence of viable microorganisms or giving growth on culture test were excluded from the study. Couples with duration of infertility of $<2$ years or infrequent intercourse or gave positive immunological tests were also excluded.

All women underwent clinical examination and transvaginal ultrasonographic (TVU) examination and hormonal profile including serum LH, FSH, prolactin and E2 levels for assurance of inclusion and exclusion criteria. Evaluation of male partner included clinical examination, scrotal ultrasonographic examination, semen analysis, immunological studies and culture test, and serum hormonal profile including serum LH, FSH and testosterone.

Enrolled couples were randomly, using sealed envelops labeled by the group title, prepared by a blinded assistant and chosen by the couples into three groups: Group L included females assigned to receive oral letrozole $5 \mathrm{mg}$ from day 3 to 7 of the menstrual cycle. Group S included females subjected to ES injury. Group LS included females received oral letrozole $5 \mathrm{mg}$ from day 3 to 7 of the menstrual cycle followed by ES injury. For all groups, ovulation was monitored and assured using TVU for evident ovulation with a dominant follicle size $>18 \mathrm{~mm}$.

Endometrial scratch technique was done as described by Maged et al.$^{[17]}$ through exposing the cervix using sterile speculum then the cervix was cleaned with sterile gauze moistened with saline. A thin catheter was introduced through the internal os then the endometrium was gently scratched by moving the catheter up and down 3 times. Patient was informed for the possibility of feeling mild cramping menstrual-like pain during the scratch and mild spotting after catheter withdrawal.

Semen was obtained after 2-3 days abstinence and sperms were prepared according to Density Gradient Sperm Wash Method and processed $\geq 36$ hours after tracking of the dominant follicles ${ }^{[18]}$. IUI was repeated for three cycles and clinical pregnancy rate (CPR) and abortion and multiple pregnancy rates were recorded.

\section{Statistical analysis}

Obtained data were presented as mean $\pm \mathrm{SD}$, numbers and percentages. The results were analyzed using paired t-test and Chi-square test (X2 test). Statistical analysis was conducted using the IBM SPSS (Version 23, 2015) for Windows statistical package. $P$ value $<0.05$ was considered statistically significant.

\section{RESULTS}

The study included 112 women with primary infertility for $>2$ years secondary to male factor and had previous failed IUI or expectant trials; 22 women were excluded and 90 women were included in the study (Fig. 1). There was non-significant $(p>0.05)$ difference between studied groups as regards data of enrolled women as shown in Table 1. 
Table 1: Patients' data recorded at time of study enrollment

\begin{tabular}{|c|c|c|c|c|c|}
\hline \multicolumn{2}{|c|}{ Data } & Group L & Group S & Group LS & $\mathrm{P}=$ \\
\hline \multicolumn{2}{|l|}{ Age (years) } & $28.5 \pm 3$ & $28.3 \pm 2.6$ & $28.6 \pm 3.7$ & 0.933 \\
\hline \multicolumn{2}{|c|}{ Duration of infertility (years) } & $4.8 \pm 0.8$ & $4.5 \pm 1.1$ & $4.4 \pm 1.2$ & 0.358 \\
\hline \multirow{3}{*}{ BMI parameters } & Body weight (kg) & $79 \pm 8.3$ & $78 \pm 9.7$ & $80.7 \pm 9.3$ & 0.515 \\
\hline & Body height (cm) & $168.2 \pm 1.8$ & $169.6 \pm 2.9$ & $168.7 \pm 2.8$ & 0.104 \\
\hline & $\operatorname{BMI}\left(\mathrm{kg} / \mathrm{m}^{2}\right)$ & $27.9 \pm 2.9$ & $27 \pm 3.4$ & $28.4 \pm 3.2$ & 0.326 \\
\hline \multicolumn{2}{|c|}{ Number of previous cycles } & $2 \pm 0.7$ & $2.2 \pm 0.6$ & $2.1 \pm 1$ & 0.616 \\
\hline \multirow{4}{*}{$\begin{array}{l}\text { Baseline serum } \\
\text { hormonal levels }\end{array}$} & FSH (mIU/ml) & $6.1 \pm 2.4$ & $5.96 \pm 3$ & $6.35 \pm 2.8$ & 0.859 \\
\hline & $\mathrm{LH}(\mathrm{mIU} / \mathrm{ml})$ & $8.22 \pm 2.3$ & $7.87 \pm 1.89$ & $8.03 \pm 2$ & 0.808 \\
\hline & Prolactin (ng/ml) & $29.72 \pm 23.4$ & $30.3 \pm 20.1$ & $31.27 \pm 19.3$ & 0.930 \\
\hline & E2 (IU/ml) & $54.14 \pm 16.4$ & $56.6 \pm 16.9$ & $59.2 \pm 15.3$ & 0.477 \\
\hline
\end{tabular}

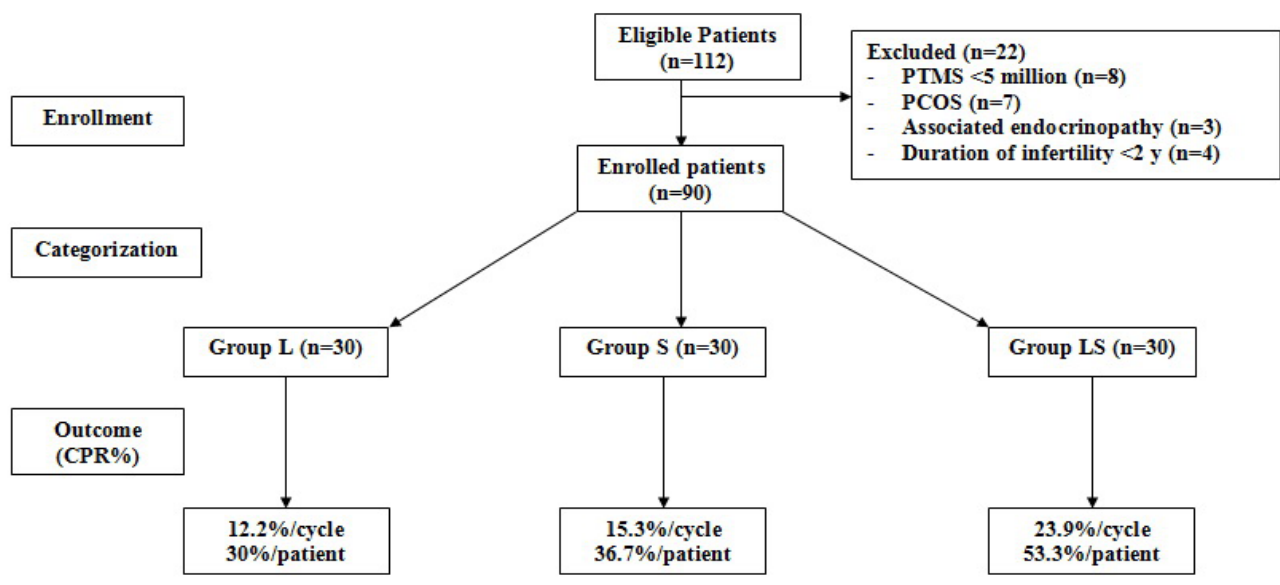

Fig. 1: Flow chart of the study

The studied women underwent 213 IUI cycle; 40 had three, 43 had two and 7 had only one cycle with nonsignificant $(p>0.05)$ difference between studied groups as regards patients' distribution between number of cycles and median number of performed cycles. Studied women gave 287 follicles of $>18 \mathrm{~mm}$ with a mean number of follicles of 3.18/female and 1.35/cycle. Mean number of follicles and follicle/cycle was significantly $(p<0.05)$ lower in women of group $\mathrm{S}$ than other groups. Mean endometrial thickness was significantly $(p=0.003)$ lower and E2 serum levels were significantly higher $(p=0.0022)$ in women of group S compared to women of other groups (Table 2, Fig.2).

Table 2: IUI cycle data of studied patients

\begin{tabular}{|c|c|c|c|c|c|}
\hline \multicolumn{2}{|c|}{ Data } & \multirow{2}{*}{$\frac{\text { Group L }}{16(53.4 \%)}$} & \multirow{2}{*}{$\frac{\text { Group S }}{14(46.7 \%)}$} & \multirow{2}{*}{$\frac{\text { Group LS }}{10(33.3 \%)}$} & \multirow{2}{*}{$\begin{array}{c}\mathrm{P}= \\
0.632\end{array}$} \\
\hline & 3 cycles & & & & \\
\hline & 2 cycles & $12(40 \%)$ & $14(46.7 \%)$ & $17(56.7 \%)$ & \\
\hline \multirow[t]{3}{*}{ No of cycles completed } & One cycle & $2(6.6 \%)$ & $2(6.6 \%)$ & $3(10 \%)$ & \\
\hline & Total & 74 & 72 & 67 & \\
\hline & Median (IQR) & $3(2-3)$ & $2(2-3)$ & $2(2-3)$ & 0.345 \\
\hline \multirow{2}{*}{ No of follicles $>18 \mathrm{~mm}$} & Total & $3.3 \pm 1$ & $2.8 \pm 0.8$ & $3.4 \pm 1.2$ & 0.035 \\
\hline & Follicle/cycle & $1.3(1-1.5)$ & $1(1-1.3)$ & $1.5(1-1.7)$ & 0.015 \\
\hline \multicolumn{2}{|c|}{ Endometrial thickness (mm) } & $9.1 \pm 1.4$ & $7.7 \pm 1.3$ & $9 \pm 1.5$ & 0.003 \\
\hline \multicolumn{2}{|l|}{ E2 (IU/ml) } & $222.3 \pm 54.9$ & $260.7 \pm 46$ & $216 \pm 57.2$ & 0.0022 \\
\hline \multirow{2}{*}{$\begin{array}{c}\text { Procedural } \\
\text { complications }\end{array}$} & Cramping pain & 0 & $2(6.6 \%)$ & $3(10 \%)$ & \\
\hline & Spotting & 0 & $2(6.6 \%)$ & $4(13.2 \%)$ & \\
\hline
\end{tabular}




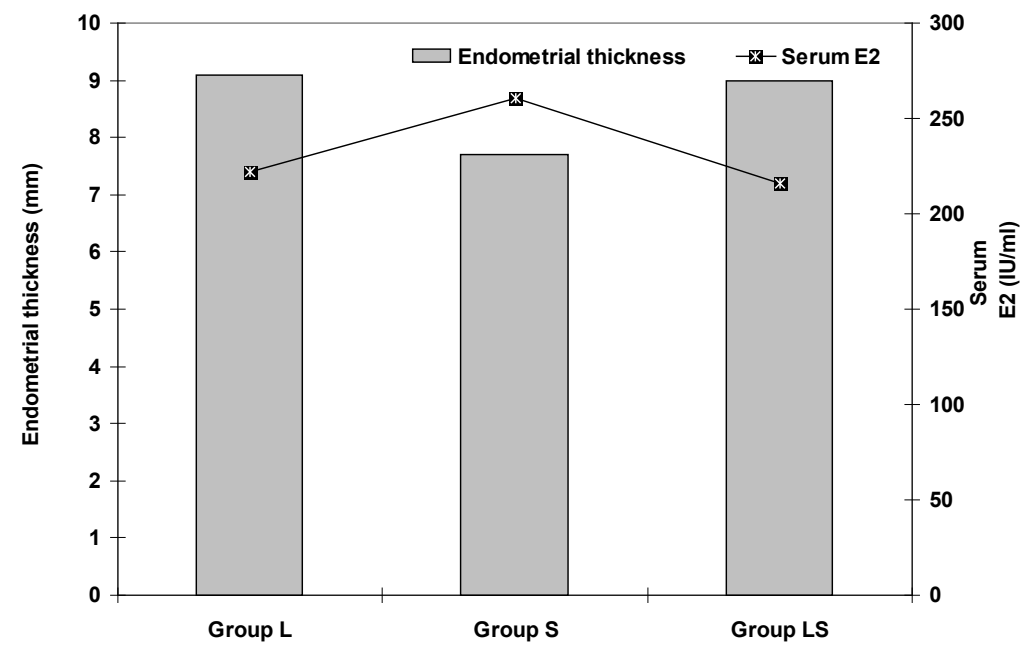

Fig. 2: Mean endometrial thickness and serum E 2 levels estimated after os

Clinical pregnancy was detected in 37 women for a total CPR of $41.1 \%$ /woman and $17.4 \%$ /cycle with significant ( $p=0.037$ and 0.043 , respectively) difference in favor of LS group. No patient developed ectopic pregnancy, but two patients of letrozole groups had multiple pregnancy. Unfortunately, during the $1 \mathrm{st}$ trimester 5 women had abortion for a rate of 5.6\%/woman and $2.3 \%$ /cycle (Table 3, Fig. 3).

Table 3: IUI cycle outcome data of studied patients

\begin{tabular}{ccccc}
\hline & Group L & Group S & Group LS & $\mathrm{P}=$ \\
\hline $\begin{array}{c}\text { Total clinical } \\
\text { pregnancy }\end{array}$ & 9 & 11 & 17 & 0.162 \\
$\begin{array}{c}\text { Clinical pregnancy/ } \\
\text { cycle }\end{array}$ & $12.2 \%$ & $15.3 \%$ & $25.4 \%$ & 0.043 \\
$\begin{array}{c}\text { Clinical pregnancy/ } \\
\text { patient }\end{array}$ & $30 \%$ & $36.7 \%$ & $56.7 \%$ & 0.037 \\
$\begin{array}{c}\text { Ectopic } \\
\text { pregnancy rate } \\
\text { Multiple }\end{array}$ & $1(11.1 \%)$ & 0 & $1(6.3 \%)$ & 0.675 \\
pregnancy rate & 0 & & 0 & 0 \\
Abortion rate & $1(11.1 \%)$ & $2(18.2 \%)$ & $2(12.5 \%)$ & 0.881 \\
\hline
\end{tabular}

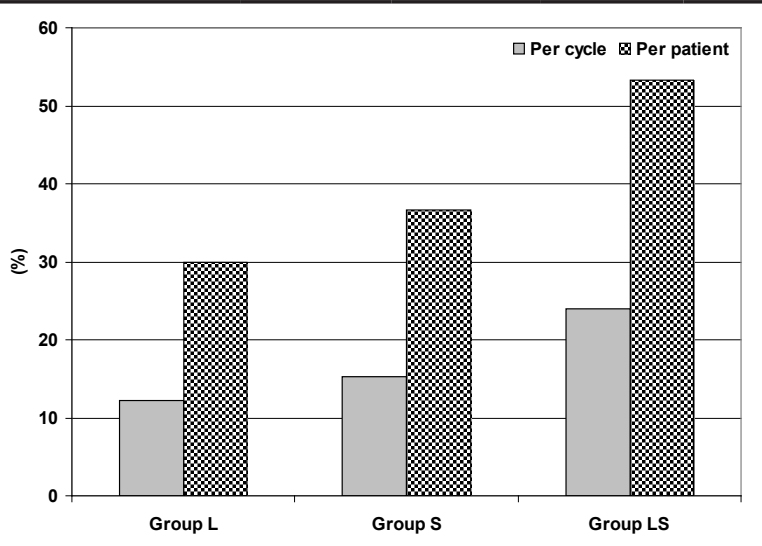

Fig. 3: Clinical pregnancy rates of studied patients

\section{DISCUSSION}

The current study relied on ovarian stimulation (OS) for preparation of patients of the two groups (Group L and LS) prior to IUI. In line with this policy to prepare women especially whose husbands were subfertile so as to increase the chance for these women to get pregnant, Peeraer et al..$^{19}$ ${ }^{20]}$ documented that OS with low-dose human menopausal gonadotrophin is superior to clomiphene citrate (CC) in IUI cycles with respect to CPR and Farquhar et al. ${ }^{[21]}$ found IUI with OS is a safe and effective treatment with higher cumulative live birth rate (LBR) for women with unexplained infertility and an unfavorable prognosis for natural conception.

Letrozole (LET), an aromatase inhibitor, was used for OS to prepare patients of groups L and LS prior to IUI. In support of the choice of letrozole for OS, Bjelica et al. (22) detected statistically significant difference in endometrial thickness, 1 st IUI cycle and 3-IUI cycle CPR between letrozole over $\mathrm{CC}$ combined with metformin in moderately obese patients with polycystic ovary syndrome (PCOS) who are resistant to stimulation with CC alone. Also, El Hachem et al. ${ }^{[23]}$ detected no differences in LBR/ IUI cycle and cumulative LBR between CC and letrozole, but multiple pregnancy rates was lower with letrozole.

Recently, Franik et $a l^{[24]}$ out of literature review reported that letrozole appears to improve live birth and pregnancy rates in subfertile women with anovulatory PCOS, compared to $\mathrm{CC}$ with similar rates of OHSS, miscarriage or multiple pregnancy rates. Also, Huang et al. ${ }^{[25]}$ performed 14,519 IUI cycles and found LBR were significantly higher in IUI cycles stimulated by CC $(8.9 \%)$, letrozole $(9.4 \%)$ and gonadotropins $(9.5 \%)$ versus $6.2 \%$ with natural-cycle IUI and the cumulative 3 -IUI cycles LBR was $25.7 \%, 26.2 \%$, and $23.7 \%$ with the use of CC, 
letrozole, and gonadotropins, respectively, versus $18.4 \%$ with natural-cycle IUI.

The current study detected beneficial effects of OS prior to IUI manifested as significantly higher number of follicles and follicle/cycle with significantly higher endometrial thickness and lower E2 serum levels in women received OS (groups L and LS) compared to women who underwent IUI without OS (group S). These data supported that previously reported ${ }^{[1,20,22,23]}$ and go in hand with the recently detected in literature ${ }^{[21,24,25]}$ concerning the use of OS prior to IUI.

Endometrial scratch (ES) was used to augment the possibility of success of IUI trial in women with (Group LS) and without (Group S) OS; such assumption go in hand with multiple previous studies ${ }^{[26,27,28,29,30]}$ assured the beneficial effect of ES and documented that endometrial injury can improve implantation rate, $\mathrm{CPR}$ and LBR in couples with unexplained infertility especially those with recurrent implantation failure after ART cycles. Recently, Viera-Molina et al. ${ }^{[1]}$ considered endometrial scratching as an effective surgical intervention for infertile women who require ART.

The proposed possibility to improve outcome of IUI using ES was evident where the CPR/cycle and per patient was non-significantly higher in patients of group ES than in patients of group L ( $15.4 \%$ vs. $12.2 \%$ and $36.7 \%$ vs. $30 \%$, respectively). These findings spot light on the near equality of the results obtained by either OS or ES alone, but was in favor of ES. Similarly, Ashrafi et al. ${ }^{[1]]}$ tried to determine the effect of ES on pregnancy rate (PR) in women with IUI failure versus no intervention and reported chemical PR of $10.7 \%$ vs. $2.7 \%$, respectively. These findings point to a fact that application of ES solo is better than OS alone, and so ES alone could be used whenever OS failed, contraindicated or inaccessible.

However, the complementary beneficial effect of both OS and ES (group LS) was superior to the effect of each intervention separately where $\mathrm{CPR} /$ cycle and per patient were significantly higher than in group L, but nonsignificantly higher than in group $\mathrm{S}$.

These findings go in hand with Maged et al. ${ }^{[17]}$ who reported significantly higher cumulative PR in patients received OS and ES than those had OS alone (39\% vs. $18.2 \%$ ) with significantly higher PR at the second and third trials in combination group. Also, Goel et al. ${ }^{[32]}$ detected significantly higher CPR with combination of OS and ES than with OS alone in women with male factor or unexplained infertility underwent IUI and concluded that ES can be used as a low cost-effective tool to improve clinical pregnancy and ongoing pregnancy rate in stimulated IUI cycles. Thereafter, Wadhwa and Mishra ${ }^{[33]}$ found ES in conjunction with controlled OS is a cost-effective and easy technique which may improve CPR in previous controlled
OS failure cycles and Vitagliano et al. ${ }^{[34]}$ suggested that ES performed once, preferably during the follicular phase of the same cycle of IUI with flexible aspiration catheters, may improve clinical pregnancy and ongoing pregnancy rates in stimulated IUI cycles.

Concerning the timing of ES, women of group LS received 5-day OS from D3-D7 of menstrual cycle and than ES was performed, in line with this timing, Wadhwa and Mishra ${ }^{[32]}$ compared pregnancy outcome by ES in early (D2-D4) and late follicular phases (D7-D9) of the same stimulation cycle versus no intervention and found CPR per protocol analysis $13.46 \%$ and $19.57 \%$ with early and late ES, respectively, versus $15.69 \%$ with no intervention.

\section{CONCLUSION}

Letrozole OS did better to prepare for IUI in infertile couple secondary to male subfertility. Endometrial scratch prior to IUI improved the chances of clinical pregnancy and could be an alternative to OS whenever OS had failed or contraindicated. ES after letrozole OS followed by IUI augments the CPR up to $53.3 \%$ patient. Wider scale study for application of these results for males with sperm count $<5$ million are recommended to evaluate these results for this patients as trial to replace the more complicated and costly ART procedures.

\section{CONFLICTS OF INTEREST}

There are no conflicts of interest.

\section{REFERENCES}

1. Viera-Molina M, Guerra-Martín MD: Analysis of the effectiveness of assisted reproduction techniques. An Sist Sanit Navar. 2018; 41(1):10716.

2. Cissen M, Bensdorp A, Cohlen BJ, Repping S, de Bruin JP, van Wely M: Assisted reproductive technologies for male subfertility. Cochrane Database Syst Rev. 2016; 2:CD000360.

3. Bhattacharya S, Harrild K, Mollison J, Wordsworth S, Tay C, Harrold A, McQueen D, Lyall H, Johnston L, Burrage J, Grossett S, Walton H, Lynch J, Johnstone A, Kini S, Raja A, Templeton A: Clomifene citrate or unstimulated intrauterine insemination compared with expectant management for unexplained infertility: pragmatic randomized controlled trial. BMJ. 2008; 337:a716.

4. Bahadur G, Homburg R, Al-Habib A: A New Dawn for Intrauterine Insemination: Efficient and Prudent Practice will Benefit Patients, the Fertility Industry and the Healthcare Bodies. J Obstet Gynaecol India. 2017; 67(2):79-85. 
5. Kop PA, Mochtar MH, O'Brien PA, Van der Veen F, van Wely M: Intrauterine insemination versus intracervical insemination in donor sperm treatment. Cochrane Database Syst Rev. 2018; 1:CD000317.

6. Kogan EA, Demura TA, Vodianoĭ VIa, Shurshalina AV: Molecular and morphological aspects of endometrial receptivity disorders at chronic endometritis. Arkh Patol. 2012;74(3):15-7.

7. Lyu BY, Li D, Zhang HL, Xin XY: Effect and regulation mechanism of Chinese Bushen Huoxue prescriptions on endometrial receptivity. Zhongguo Zhong Yao Za Zhi. 2018; 43(10):2014-9.

8. Revel A: Defective endometrial receptivity. Fertil Steril. 2012; 97(5):1028-32.

9. Katzorke N, Vilella F, Ruiz M, Krüssel JS, Simón $\mathrm{C}$ : Diagnosis of Endometrial-Factor Infertility: Current Approaches and New Avenues for Research. Geburtshilfe Frauenheilkd. 2016; 76(6):699-703.

10. Bellver J, Simón C: Implantation failure of endometrial origin: what is new? Curr Opin Obstet Gynecol. 2018; 30(4):229-236.

11. Lu X, Wu Y, Gao XH, Wang YW, Wang L, Sun $\mathrm{XX}$ : Effect of letrozole on estradiol production and P450 aromatase messenger RNA expression of cultured luteinized granulosa cells from women with and without endometriosis. Fertil Steril. 2012; 98(1):131-5.

12. Jin SJ, Jung JA, Cho SH, Kim UJ, Choe S, Ghim JL, Noh YH, Park HJ, Kim JC, Jung JA, Lim HS, Bae KS: The pharmacokinetics of letrozole: association with key body mass metrics. Int J Clin Pharmacol Ther. 2012; 50(8):557-65.

13. Xia X, Guo L, Su J, Fang X: Effect of letrozole on endometrosis and apoptosis of ectopic endometrial cells in rats.

14. Ortega I, Sokalska A, Villanueva JA, Cress AB, Wong DH, Stener-Victorin E, Stanley SD, Duleba AJ: Letrozole increases ovarian growth and Cyp17a1 gene expression in the rat ovary. Fertil Steril. 2013; 99(3):889-96.

15. Hole S, Pedersen AM, Hansen SK, Lundqvist J, Yde CW, Lykkesfeldt AE: New cell culture model for aromatase inhibitor-resistant breast cancer shows sensitivity to fulvestrant treatment and cross-resistance between letrozole and exemestane. Int J Oncol. 2015; 46(4):1481-90.

16. Merviel P, Heraud MH, Grenier N, Lourdel E, Sanguinet $\mathrm{P}$, Copin H: Predictive factors for pregnancy after intrauterine insemination (IUI): an analysis of 1038 cycles and a review of the literature. Fertil Steril. 2010; 93(1):79-88.

17. Maged AM, Al-Inany H, Salama KM, Souidan II, Abo Ragab HM, Elnassery N:Endometrial Scratch Injury Induces Higher Pregnancy Rate for Women With Unexplained Infertility Undergoing IUI With Ovarian Stimulation: A Randomized Controlled Trial. Reprod Sci. 2016; 23(2):239-43.

18. Akram A, Imtiaz SA, Jahan S: Effect of sperm parameters on intrauterine insemination pregnancy rate. J Coll Physicians Surg Pak. 2008; 18(6):3426.

19. Peeraer K, Debrock S, De Loecker P, Tomassetti C, Laenen A, Welkenhuysen M, Meeuwis L, Pelckmans S, Mol BW, Spiessens C, De Neubourg D, D'Hooghe TM: Low-dose human menopausal gonadotrophin versus clomiphene citrate in subfertile couples treated with intrauterine insemination: a randomized controlled trial. Hum Reprod. 2015; 30(5):1079-88.

20. Peeraer K, Luyten J, Tomassetti C, Verschueren S, Spiessens C, Tanghe A, Meuleman C, Debrock S, Dancet E, D'Hooghe T: Cost-effectiveness of ovarian stimulation with gonadotrophin and clomiphene citrate in an intrauterine insemination programme for subfertile couples. Reprod Biomed Online. 2018; 36(3):302-10.

21. Farquhar CM, Liu E, Armstrong S, Arroll N, Lensen S, Brown J: Intrauterine insemination with ovarian stimulation versus expectant management for unexplained infertility (TUI): a pragmatic, open-label, randomised, controlled, two-centre trial. Lancet. 2018; 391(10119):441-50.

22. Bjelica A, Trninić-Pjević A, Mladenović-Segedi L, Cetković N, Petrović D: Comparison of the efficiency of clomiphene citrate and letrozole in combination with metformin in moderately obese clomiphene citrate-resistant polycystic ovarian syndrome patients. Srp Arh Celok Lek. 2016; 144(3-4):146-50

23. El Hachem H, Antaki R, Sylvestre C, Lapensée L, Legendre G, Bouet PE: Timing therapeutic donor inseminations in natural cycles: human chorionic 
gonadotrophin administration versus urinary LH monitoring. Reprod Biomed Online. 2017; 35(2):174-9.

24. Franik S, Eltrop SM, Kremer JA, Kiesel L, Farquhar C: Aromatase inhibitors (letrozole) for subfertile women with polycystic ovary syndrome. Cochrane Database Syst Rev. 2018; 5:CD010287.

25. Huang S, Wang R, Li R, Wang H, Qiao J, Mol BWJ: Ovarian stimulation in infertile women treated with the use of intrauterine insemination: a cohort study from China. Fertil Steril. 2018 May;109(5):872-8.

26. Tiboni GM, Giampietro F, Gabriele E, Di Donato $\mathrm{V}$, Impicciatore GG: Impact of a single endometrial injury on assisted reproductive technology outcome: a preliminary observational study. J Reprod Med. 2011;56(11-12):504-6.

27. Potdar N, Gelbaya T, Nardo LG: Endometrial injury to overcome recurrent embryo implantation failure: a systematic review and meta-analysis. Reprod Biomed Online. 2012; 25(6):561-71.

28. Shohayeb A, El-Khayat W: Does a single endometrial biopsy regimen (S-EBR) improve ICSI outcome in patients with repeated implantation failure? A randomised controlled trial. Eur J Obstet Gynecol Reprod Biol. 2012;164(2):176-9.

29. El-Toukhy T, Sunkara S, Khalaf Y: Local endometrial injury and IVF outcome: a systematic review and meta-analysis. Reprod Biomed Online. 2012; 25(4):345-54.

30. Gibreel A, Badawy A, El-Refai W, El-Adawi N Endometrial scratching to improve pregnancy rate in couples with unexplained subfertility: a randomized controlled trial. J Obstet Gynaecol Res. 2013;39(3):680-4.

31. Ashrafi M, Tehraninejad ES, Haghiri M, Masomi M, Sadatmahalleh SJ, Arabipoor A: The effect of endometrial scratch injury on pregnancy outcome in women with previous intrauterine insemination failure: A randomized clinical trial. J Obstet Gynaecol Res. 2017; 43(9):1421-7.

32. Goel T, Mahey R, Bhatla N, Kalaivani M, Pant S, Kriplani A: Pregnancy after endometrial scratching in infertile couples undergoing ovulation induction and intrauterine insemination cycles-a randomized controlled trial. J Assist Reprod Genet. 2017; 34(8):1051-1058

33. Wadhwa L, Mishra M: Therapeutic Efficacy of Endometrial Scratching in Repeated Controlled Ovarian Stimulation (COS) Failure Cycles. J Hum Reprod Sci. 2018;11(1):59-71.

34. Vitagliano A, Noventa M, Saccone G, Gizzo S, Vitale SG, Laganà AS, Litta PS, Saccardi C, Nardelli GB, Di Spiezio Sardo A: Endometrial scratch injury before intrauterine insemination: is it time to reevaluate its value? Evidence from a systematic review and meta-analysis of randomized controlled trials. Fertil Steril. 2018; 109(1):84-96. 